\title{
Biogas Production from Brewer's Yeast Using an Anaerobic Sequencing Batch Reactor
}

\author{
Gregor Drago Zupančič ${ }^{1,2}$, Mario Panjičko ${ }^{1}$ and Bruno Zelić3* \\ ${ }^{1}$ Sustainable Technologies Development Centre Ltd, Dragutina Golika 63, HR-10000 Zagreb, Croatia \\ ${ }^{2}$ National Institute of Chemistry, Hajdrihova 19, SI-1000 Ljubljana, Slovenia \\ ${ }^{3}$ University of Zagreb, Faculty of Chemical Engineering and Technology, Marulićev trg 19, \\ HR-10000 Zagreb, Croatia
}

Received: November 24, 2016 Accepted: February 24, 2017

\begin{abstract}
Summary
Renewable energy sources are becoming increasingly important in the beverage and food industries. In the brewing industry, a significant percentage of the used raw materials finishes the process as secondary resource or waste. The research on the anaerobic digestion of brewer's yeast has been scarce until recent years. One of the reasons for this is its use as a secondary resource in the food industry and as cattle feed. Additionally, market value of brewer's yeast is higher than its energy value. Due to the increase of energy prices, brewer's yeast has become of interest as energy substrate despite its difficult degradability in anaerobic conditions. The anaerobic co-digestion of brewer's yeast and anaerobically treated brewery wastewater was studied using a pilot-scale anaerobic sequencing batch reactor (ASBR) seeded with granular biomass. The experiments showed very good and stable operation with an organic loading rate of up to $8.0 \mathrm{~kg} /\left(\mathrm{m}^{3}\right.$.day $)$, and with a maximum achieved organic loading rate of $13.6 \mathrm{~kg} /\left(\mathrm{m}^{3} \cdot\right.$ day) in a single cycle. A specific biogas productivity of over $0.430 \mathrm{~m}^{3} / \mathrm{kg}$ of the total chemical oxygen demand (COD) inserted, and total COD removal efficiencies of over $90 \%$ were achieved. This study suggests that the brewer's yeast can be successfully digested in an ASBR without adverse effects on the biogas production from brewer's yeast/wastewater mixtures of up to $8 \%$ (by volume). By using the brewer's yeast in the ASBR process, the biogas production from brewery wastewater could be increased by $50 \%$.
\end{abstract}

Key words: anaerobic digestion, ASBR, biogas, brewer's yeast

\section{Introduction}

As a result of rising fuel costs and urgent need for the reduction of industrial carbon footprint (1), renewable energy sources are becoming increasingly important in the beverage and food industries. In the brewing industry, a significant percentage of the used raw materials finishes the process as secondary resource or waste. The anaerobic digestion offers the possibility to treat these substrates successfully in order to produce biogas, which can substitute natural gas needed in the brewing process.

The brewing wastewater is the dominant waste stream in the brewing industry and as such has received significant attention in recent times. Usually, this brewing wastewater is treated in anaerobic systems using granular biomass (2). Reactors used for these treatments are up-flow anaerobic sludge blanket (UASB) systems $(3,4)$, adapted

*Corresponding author: Phone: +385 14597 281; Fax: +385 14597 260; E-mail: bzelic@fkit.hr 
expanded granular sludge bed (EGSB) reactors (5) and more recently anaerobic sequencing batch reactors (ASBR) (6). However, flow-through UASB reactors are conventionally high-load reactors and have significant problems when degrading high-solid substrates (7), which is most certainly the case when adding yeast to the wastewater. As a result, equipment suppliers usually prescribe a limit for total solids of $5 \mathrm{~g} / \mathrm{L}$. In such cases, the ASBR technology can offer a solution for the mentioned problem regarding the degradation of high-solid substrates. In these reactors the granulated sludge tolerates higher concentrations of solids, due to the settling stage of the operation.

The biogas production by anaerobic digestion of the brewery wastewater can offer substantial savings with respect to the energy demands of the brewery. Kormelinck (8) reports that up to $20 \%$ of the natural gas can be substituted with methane from the produced biogas. Moreover, recent research suggests that these savings can even be increased, since there are additional substrates suitable for biogas production already available in most of the breweries. Agler et al. (9) reported the anaerobic digestion of the primary brewery wastewater sludge in an ASBR system and achieved a $7.6 \%$ increase in methane production. On the other hand, Bocher et al. (10) offered the treatment of secondary residuals from an UASB effluent and achieved an $8 \%$ increase in methane generation. Other substrates available in the breweries that have been identified as suitable for biogas generation are yeast and brewer's spent grain.

The research on the anaerobic digestion of brewer's yeast and brewer's spent grain has been scarce until recent years. One of the reasons for this is because these substrates have so far been used as a secondary resource in the food industry and as cattle feed (11). Furthermore, they have had a market value higher than their energy value. It was only recently, due to the increase of energy prices, that these substrates have become of interest as energy substrates. The other reason for these substrates being of little interest is their difficult degradability in anaerobic conditions. Neira and Jeison (12) were the first to report a successful anaerobic digestion of brewer's yeast in combination with the brewery wastewater. In our previous work (13), we followed and thoroughly researched the possibilities of brewer's yeast co-digestion with the brewery wastewater under different conditions. We have found that with brewer's yeast/wastewater mixtures of up to $1.1 \%$ (by volume) there were no negative impacts on the digestion process, provided that the organic loading rate of the brewery wastewater treatment reactor (EGSB) allowed additional loading. Experiments with more concentrated mixtures showed adverse effects, which were reflected in reduced total chemical oxygen demand (tCOD) degradation efficiencies and biogas production, regardless of the organic loading rate. A full-scale anaerobic codigestion plant treating brewer's yeast and brewery wastewater mixtures has now been in operation for over five years in a local brewery in Slovenia, and it has only shown positive results (14). There are no adverse effects on technical operation of the plant. Moreover, an average product value of 0.2 euro cent per litre of brew through increased methane usage is achieved.
The objective of this study is to demonstrate a feasible use of brewer's yeast as an energy co-substrate by digestion of yeast/wastewater mixtures in an ASBR system at volume ratios higher than $1.1 \%$. Such cases would occur when the brewery wastewater treatment system is at full capacity and does not allow additional organic loading by adding the brewer's yeast to the raw brewery wastewater. The treatment in an additional ASBR with a mixture of anaerobically digested brewery wastewater and yeast could offer a solution for the brewer's yeast digestion.

\section{Materials and Methods}

\section{ASBR reactor}

A pilot-scale anaerobic sequencing batch reactor (ASBR) made of Schott glass (Büchi Glass, Uster, Switzerland) with an operational volume of $30 \mathrm{~L}$ and an exchange volume of $10 \mathrm{~L}$ was used during the experimental work (Fig. 1). A stirrer RZR 2021 (Heidolph Instruments, Schwabach, Germany) at $70 \mathrm{rpm}$ provided mixing of the substrate and biomass inside the reactor. The biogas production was continuously recorded with an ADM 2000 gas flow meter (Agilent Technologies, Wilmington, DE, USA). The temperature in the reactor was controlled at $(32 \pm 1)$ ${ }^{\circ} \mathrm{C}$. The reactor was also equipped with an on-line differential $\mathrm{pH}$ probe (pHD-S sc; Hach-Lange, Düsseldorf, Germany). The volume fraction of methane $(\varphi)$ in biogas was estimated by installing a custom-made semi-dry absorption unit during the fourth cycle of every experiment, operating with $\mathrm{NaOH}$ pellets (Merck Millipore, Darmstadt, Germany). The same pellets were used to make a $20 \%$ (by mass) solution for neutralisation.

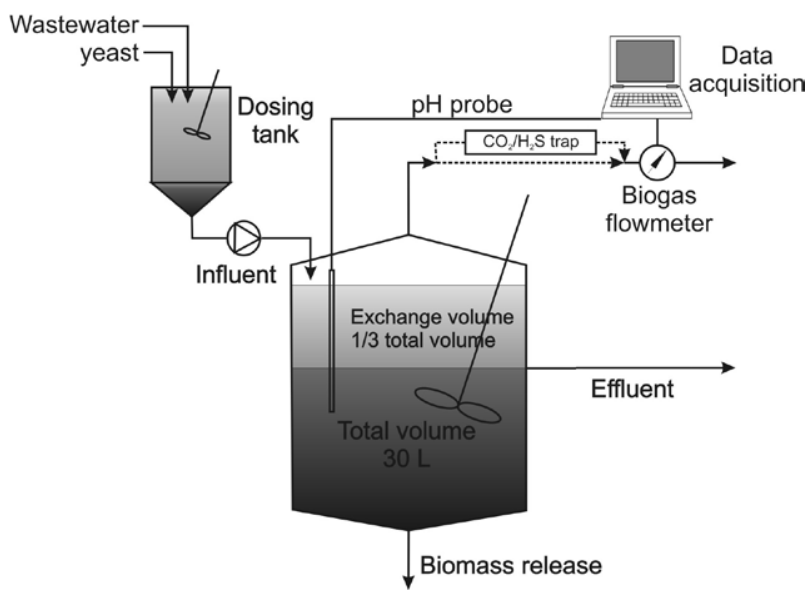

Fig. 1. Experimental anaerobic sequencing batch reactor (ASBR) setup

\section{Seed sludge (inoculum)}

The seed sludge was taken from an operational expanded granular sludge bed (EGSB) reactor at the local brewery (Laško, Slovenia) in which the brewery wastewater was treated at $(35 \pm 2){ }^{\circ} \mathrm{C}$, depending on the seasonal weather. The sludge was typically granular with a total solid concentration $\gamma(\mathrm{TS})=80-100 \mathrm{~g} / \mathrm{L}$, of which $90 \%$ were 
volatile solids (VS). A total of $15 \mathrm{~L}$ of the sludge was used as inoculum, which constitutes $50 \%$ of operational reactor volume.

\section{Wastewater and brewer's yeast}

The wastewater used in the experiments was taken directly from the effluent of the same EGSB reactor from which the inoculum was collected. Typically, it contained mass concentrations of TS and VS of $(1.0 \pm 0.2)$ and $(0.3 \pm 0.1)$ $\mathrm{g} / \mathrm{L}$, respectively, with the total chemical oxygen demand concentration $\gamma(\mathrm{tCOD})$ in the range of $300-600 \mathrm{mg} / \mathrm{L}$ and no anaerobic biodegradability. The anaerobic degradability of the collected wastewater was investigated in the first cycle of the first experiment and it showed to be negligible and within the measurement uncertainty of the ADM 2000 biogas flow meter (Agilent Technologies). The temperature of the collected and used wastewater was $(35 \pm 2){ }^{\circ} \mathrm{C}$, depending on the seasonal weather. The excess yeast was collected directly from the yeast collection tank of the lager beer production line of the local brewery at a temperature of approx. $(8 \pm 3){ }^{\circ} \mathrm{C}$. Typically, the mass concentrations of TS, VS and tCOD in yeast were (185.0 \pm 5.0$)$, $(175.0 \pm 5.0)$ and $(265.0 \pm 15.0) \mathrm{g} / \mathrm{L}$, respectively. The yeast and wastewater were mixed in a dosing tank of the pilot plant prior to the filling of the reactor. Each batch $(10 \mathrm{~L})$ was neutralised to $\mathrm{pH}=6.5$ using a $20 \%$ (by mass) $\mathrm{NaOH}$ solution. As previously stated, the effluent from the EGSB reactor had a temperature of $(35 \pm 2){ }^{\circ} \mathrm{C}$, while the waste yeast had a temperature of $(8 \pm 3){ }^{\circ} \mathrm{C}$. By mixing the substrates on site, a mixture temperature of $(32 \pm 1){ }^{\circ} \mathrm{C}$ was readily achieved without the use of any additional heating.

\section{ASBR operation}

A series of eight experiments were performed, each of them having five cycles. The cycles were adapted to the actual beer production process in the local brewery and the consequent wastewater and yeast discharge, which were repeated conventionally on a weekly basis. Therefore, the first four cycles were operated for $24 \mathrm{~h}$ each, while the fifth cycle (over the weekend) was operated for $72 \mathrm{~h}$. Each cycle consisted of four phases: fill, react, settle and release. The fill phase lasted approx. $1 \mathrm{~h}$, when the mixture of wastewater and yeast was pumped into the reactor. The react phase was already on-going while pumping, and it continued for an additional $20 \mathrm{~h}(68 \mathrm{~h}$ in the fifth cycle). The settling phase lasted approx. $2 \mathrm{~h}$. This was followed by the release phase, lasting 1 hour.

The experiments were carried out using various yeast and wastewater mixture ratios. In experiment 1 , a mixture of $2 \%$ (by volume) of yeast in the wastewater was used in all 5 cycles. Experiments 2-6 were performed with 4, 6, 8, 10 and $12 \%$ (by volume) mixture in all cycles, respectively. During the first cycle in experiment 7 or $10 \%$ (by volume) of yeast in the wastewater was used, in cycles 2-4 11 $\%$ (by volume) and in the fifth cycle $17 \%$ (by volume) mixture was used. In experiment 8 , during the first two cycles $9 \%$ (by volume) mixture was used, in cycles 3 and $410 \%$ (by volume) and in cycle $522 \%$ (by volume) mixture was used. The mixtures in experiments 7 and 8 were selected to match the quantity of waste yeast in experiment 6 and to improve the efficiency of the process by taking into account the prolonged fifth cycle. Samples were taken from each influent and effluent analysing total chemical oxygen demand (tCOD). The dissolved COD (dCOD) was determined only in the samples from the effluent. The volatile fatty acids (VFAs) of the effluents were analysed for every experiment cycle with the highest organic loading rate (OLR). After experiment 6 , the biomass accumulation was estimated based on the accumulated TS and VS.

\section{Analytical methods}

The mass concentrations of total solids (TS), volatile solids (VS), total Kjeldhal nitrogen (TKN) and ammonia nitrogen $\left(\mathrm{NH}_{4}-\mathrm{N}\right)$ were analysed according to APHA standard methods (15). The mass concentrations of tCOD and $\mathrm{dCOD}$ were monitored and analysed during all cycles of the conducted experiments. The VFA content was determined only once in all cycles, and mass concentrations of TKN and $\mathrm{NH}_{4}-\mathrm{N}$ only once in cycles 2, 3, 4, 5, 6 and three times in cycles 7 and 8 in average samples. The COD was determined in accordance with the procedure of ISO 6060:1989 (16). The dissolved portion of the COD was determined by filtration through an ashless black ribbon filter (Whatman, Dassel, Germany). The VFAs were extracted from the samples with diethyl ether according to the procedure of Holdeman et al. (17) and analysed with a HP5890 gas chromatograph (Hewlett Packard, Wilmington, DE, USA) with a split/splitless injector and a flame ionization detector, equipped with a fused silica capillary column of $30 \mathrm{~m}$ length, $0.25 \mathrm{~mm}$ diameter and $0.25 \mu \mathrm{m}$ stationary phase thickness (model 20988-03A; Supelco, Bellefonte, PA, USA). The VFA content was determined using an internal standard method. The temperatures of the injector, detector and the column were 185, 290 and $75^{\circ} \mathrm{C}$, respectively. All methods were kept under continuous statistical control. The control charts were created from the results obtained in the analysis of the reference material (laboratory working reference standards). In addition, the laboratory participated in proficiency tests (18) and a good performance was obtained in all determinations. The measurement uncertainties of the measured concentrations of COD, TS and VS were always below $8 \%$ and the uncertainty of the biogas measurements was $3 \%$ (95\% confidence limit). The measurement uncertainty was evaluated according to Drolc et al. (19) and the principles of the Guide to the Expression of Uncertainty in Measurement (20).

\section{Results and Discussion}

\section{Process operation}

The experiments of the anaerobic co-digestion of brewer's wastewater and brewer's yeast in an ASBR system were performed during a total of 40 cycles divided into eight experiments as described in previous sections. The major expected drawback during the operation of such process was the accumulation of yeast solids throughout the duration of the process in the settled biomass of the reactor. However, the settleability of the yeast solids was very low compared to the settleability of the granulated biomass, and the expected accumulation of solids did not 
present a problem. In addition, in the first cycle of experiment 1 , the anaerobically digested wastewater, which was used for dilution was tested for any eventual residual biodegradability. The result is presented in Fig. 2 and it shows that no statistically significant increase of biogas production was observed, compared to the background (respiration of inoculum).

Biogas production and $\mathrm{pH}$ were monitored on-line and are shown in Figs. 2 and 3. The average mass concen- trations of the tCOD in the influent $\left(\mathrm{tCOD}_{\text {inf }}\right)$ and $\mathrm{dCOD}$ in the effluent $\left(\mathrm{dCOD}_{\text {eff }}\right)$, the mass concentrations of TKN and $\mathrm{NH}_{4}-\mathrm{N}$ and the volume fraction of methane in biogas are shown in Table 1. The COD removal, specific biogas production (SBP) and organic loading rate (OLR) are shown in Figs. 4 and 5. The VFA mass fractions are shown in Table 2. From the obtained results, it could be concluded that the process operated very well with yeast/wastewater mixtures of up to $8 \%$, by volume (experiments 1 to

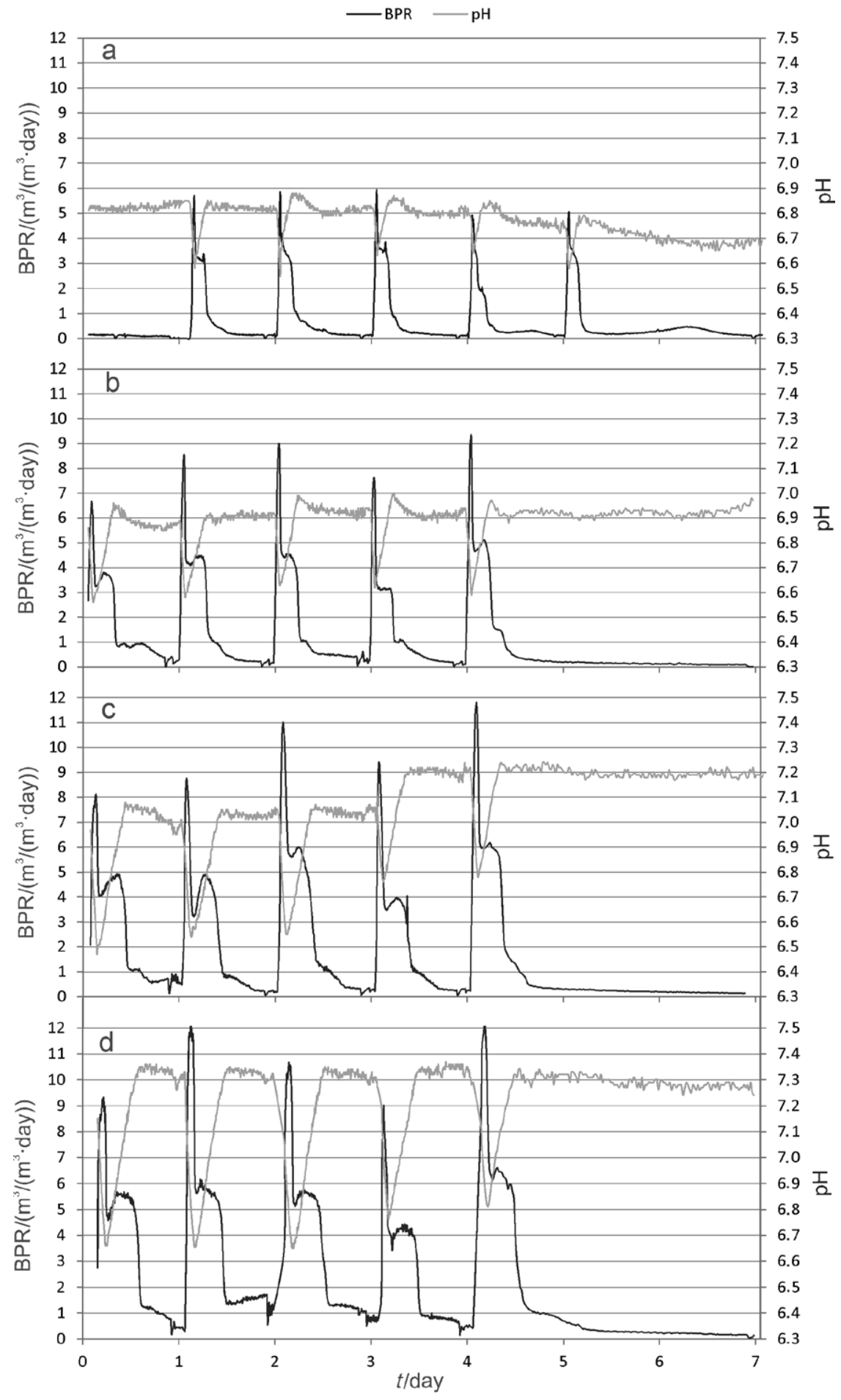

Fig. 2. Biogas production rate (BPR) and $\mathrm{pH}$ values during: a) experiment $1, \mathrm{~b}$ ) experiment 2 , c) experiment 3 , and d) experiment 4 
4, Figs. 2 and 4). This corresponds to an OLR of $7.0 \mathrm{~kg} /$ $\left(\mathrm{m}^{3} \cdot\right.$ day), tCOD removal of over $80 \%$ and $\mathrm{dCOD}_{\text {eff }} / \mathrm{tCOD}_{\text {inf }}$ removal of over $94 \%$. The VFA concentrations were very low, which confirms the very good operation. Similar results of the treatment of brewery slurry were reported in our previous research (21) and of the treatment of brewery wastewater by other authors (6). By increasing the OLR of the treated yeast/wastewater mixtures from 10 to $12 \%$ (by volume), the COD degradation was substantial- ly lower with tCOD removal of below $80 \%$ and $\mathrm{dCOD}_{\text {eff }} /$ $\mathrm{tCOD}_{\text {inf }}$ of below $88 \%$. However, the process was still stable. During the longer lasting fifth cycle, the performances slightly improved, which is evident also when $17 \%$ yeast/wastewater mixture (by volume) with a cycle time of 3 days was used, where the tCOD removal increased to $81.4 \%$ and the $\mathrm{dCOD}_{\text {eff }} / \mathrm{tCOD}_{\text {inf }}$ to $88.5 \%$ (Fig. 5). The process efficiency was reflected in the change of volatile fatty acid mass fractions in the effluent as well (Table 2),

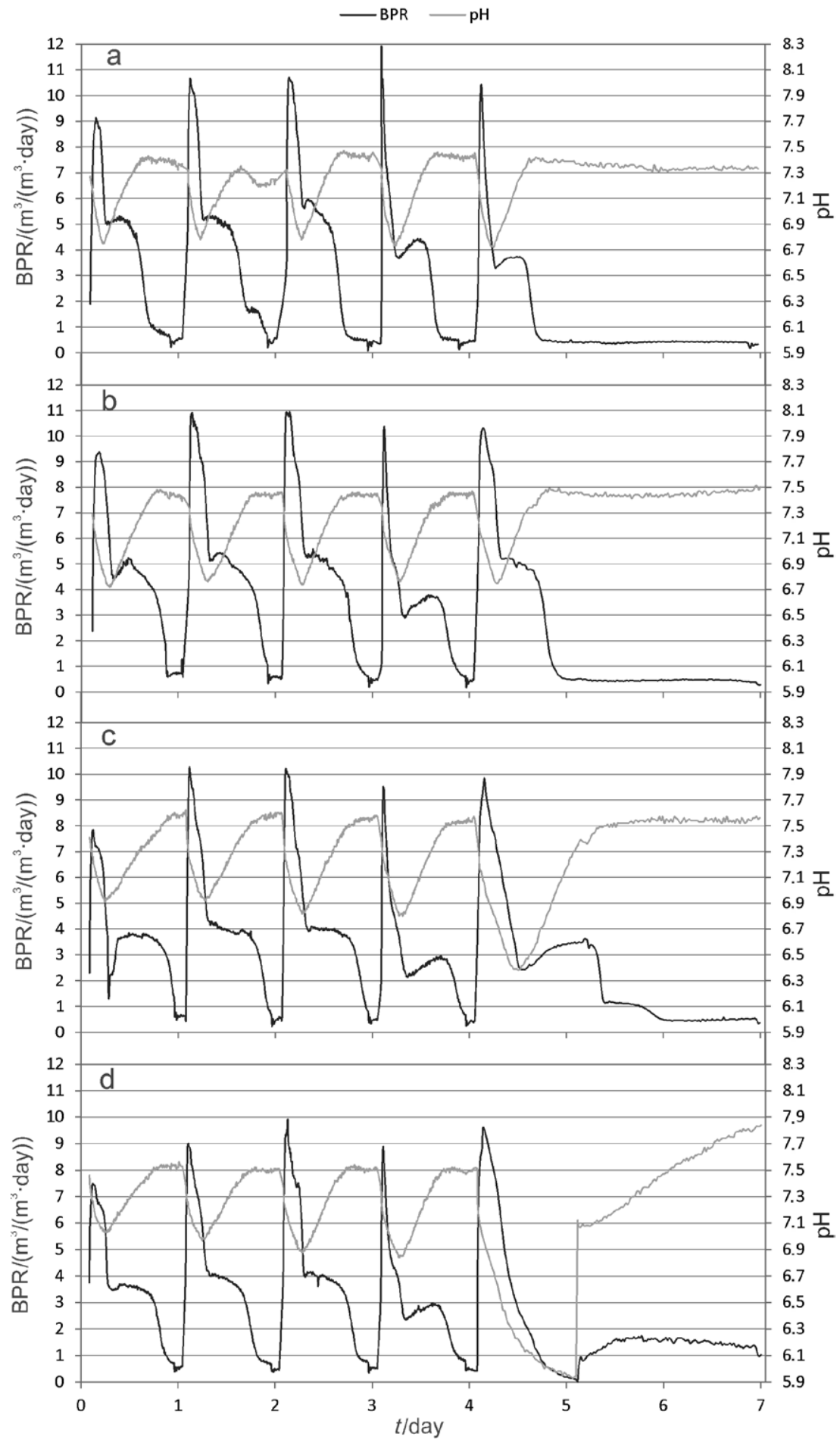

Fig. 3. Biogas production rate (BPR) and $\mathrm{pH}$ values during: a) experiment $5, \mathrm{~b}$ ) experiment 6 , c) experiment 7 , and d) experiment 8 


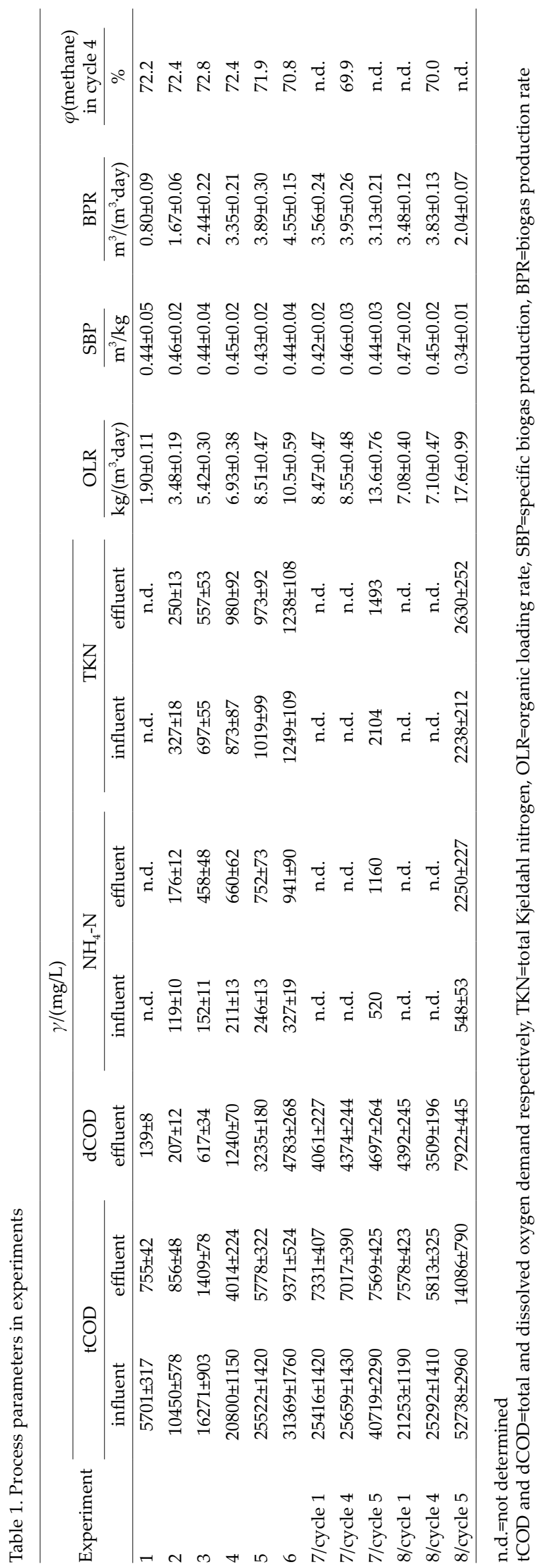

which increased by increasing the load and slightly decreased during the fifth cycle of the experiment with the $17 \%$ yeast/wastewater mixture (by volume). When a yeast/wastewater mixture of up to $17 \%$ (by volume) was used, the observed mass fractions of the acetic and propionic acids were very low. This indicated a very good performance of the methanogenic microorganisms and a limiting step of the degradation of yeast solids. The maximum achieved operational OLR was $13.6 \mathrm{~kg} /$ $\left(\mathrm{m}^{3} \cdot\right.$ day $)$, which is comparable with the results obtained by Baloch et al. (4). They managed to successfully treat the brewery wastewater in a phase-separated granular bed reactor at a similar OLR of $13.38 \mathrm{~kg} /\left(\mathrm{m}^{3} \cdot\right.$ day). Further increase of the OLR to $17.6 \mathrm{~kg} /\left(\mathrm{m}^{3}\right.$.day) with a higher volume ratio of yeast/wastewater mixture of $22 \%$ resulted in process failure. The process resembled a classical organic overload, with a massive increase in VFA production and a consequent decrease of $\mathrm{pH}$ to 6.0 (Fig. 3). Therefore, we can safely state that the OLR was too high. Although an immediate intervention was performed by an automated system, by adding $\mathrm{NaOH}$ when the $\mathrm{pH}$ reached 6.0 and correcting it to $\mathrm{pH}=7.0$ (Fig. 3), the system never fully recovered to its original performance capability. Even after completing the cycle (minimum biogas production), the mass fraction of the acids was still very high (Table 2). A few later process recovery attempts were made and recovery was achieved after 5 days (effluent $\gamma($ tCOD) $<10000$ $\mathrm{mg} / \mathrm{L})$, at an OLR of approx. $6.0 \mathrm{~kg} /\left(\mathrm{m}^{3} \cdot\right.$ day $)$. The performance was less than $45 \%$ of its original efficiency, prolonging the original daily cycle to two days. Moreover, a visual disintegration of the granular sludge was detected, considerably reducing the granular size and consequently its settleability. In all, the performance was severely compromised, although not completely suspended. We estimated that an OLR of $2.0 \mathrm{~kg} /\left(\mathrm{m}^{3} \cdot\right.$ day) could be achieved in these conditions, however, such a low OLR would not represent a feasible performance when compared to the original capabilities.

\section{Biogas production}

The biogas production and $\mathrm{pH}$ values during the experiments are presented in Figs. 2 and 3. The values of the specific biogas production (SBP) are presented in Figs. 4 and 5. On average, when the process performance was good, a SBP of over $0.430 \mathrm{~m}^{3} / \mathrm{kg}$ was achieved. As expected, the biogas production rate (BPR) was higher at a higher OLR, peaking at $4.55 \mathrm{~m}^{3} /\left(\mathrm{m}^{3}\right.$.day) during experiment 6 (yeast/wastewater mixture of $12 \%$ by volume). The methane content was in the range of 70-73\%. Similar results were also presented by Shao et al. (6), where a SBP of $0.480 \mathrm{~m}^{3} / \mathrm{kg}$ and a BPR of $2.4 \mathrm{~m}^{3} /\left(\mathrm{m}^{3} \cdot\right.$ day $)$ were achieved at an OLR of $5.0 \mathrm{~kg} /\left(\mathrm{m}^{3} \cdot\right.$ day). The BPR showed a typical profile. At first, the biogas from dissolved organic matter was produced (a distinctive peak at the beginning of the reaction phase). Later on, a less distinctive peak of degrading solids, which was dissipated over a longer period of time due to the slower degradability, was observed. Fig. 3 presents the biogas production in experiments 5-8, where it is clear that the biogas production in experiments 6-8 was not completely finished before the cycle was over, and this was reflected in the acid mass fractions in the effluent as well (Table 2). 


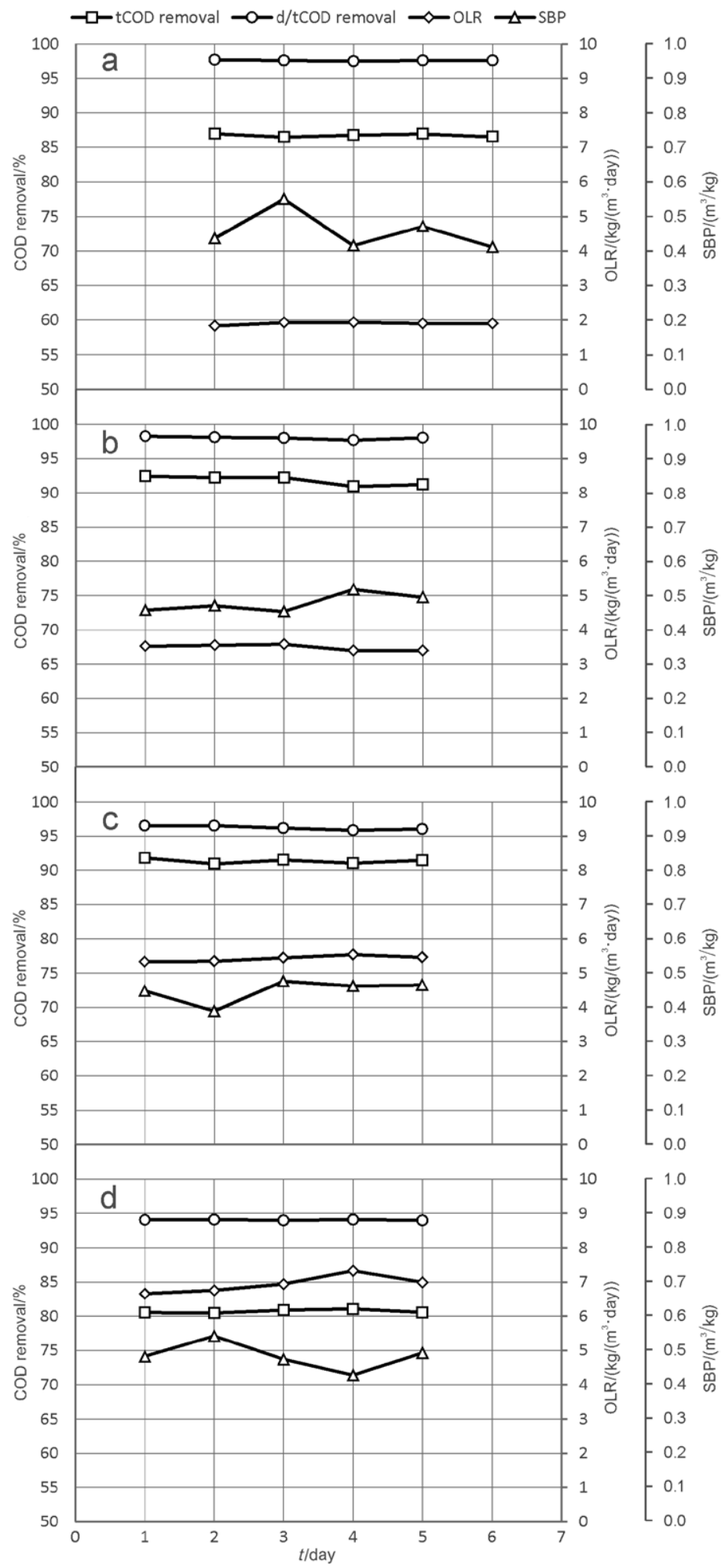

Fig. 4. Chemical oxygen demand (COD) removal, organic loading rate (OLR) and specific biogas production (SBP) on insoluble COD basis during: a) experiment 1, b) experiment 2 , c) experiment 3 , and d) experiment 4

Taking into account the obtained results, it can be stated that under the presented conditions of a 1-day cycle, an OLR of over $8.0 \mathrm{~kg} /\left(\mathrm{m}^{3}\right.$.day) would not be advisable over longer periods of time. Moreover, a maximum OLR of 13.6 $\mathrm{kg} /\left(\mathrm{m}^{3} \cdot\right.$ day $)$ is achievable in a single cycle but with a cycle duration of at least two days. It can also be concluded that a mixture of brewer's yeast and wastewater does act, in a certain way, very similarly in anaerobic digestion as does the brewery wastewater itself, which is confirmed by comparing the results of this study with the results obtained by other authors $(4,6)$. The concentration of yeast in the yeast/ wastewater mixture does not affect the anaerobic digestion 


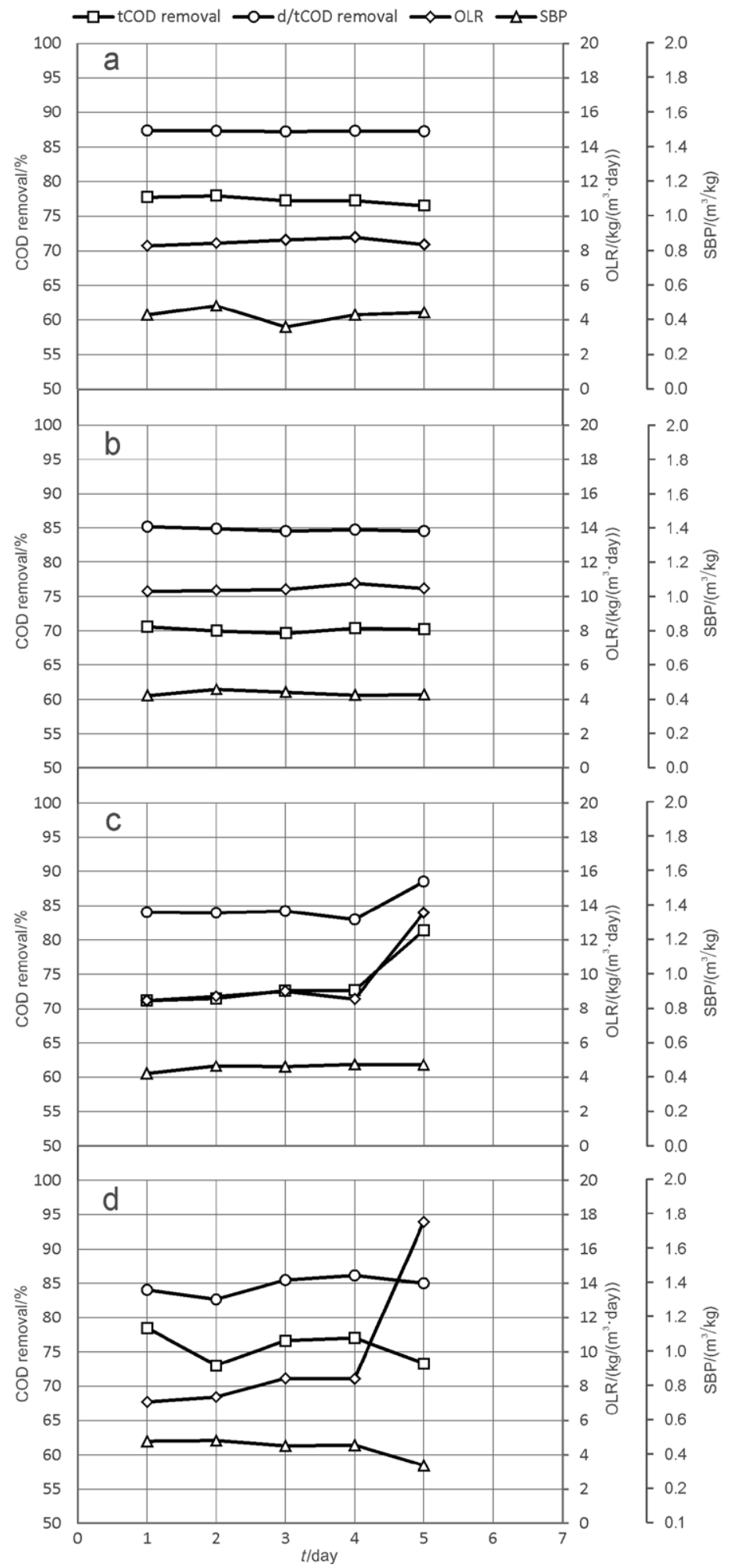

Fig. 5. Chemical oxygen demand (COD) removal, organic loading rate (OLR) and specific biogas production (SBP) on insoluble COD basis during: a) experiment 5, b) experiment 6, c) experiment 7 , and d) experiment 8

in ASBR significantly; the increase of OLR due to yeast addition to the mixture has the predominating impact. Contrary to our previous research (13), high ratios of yeast in yeast/wastewater mixture (over $1.1 \%$ by volume) do not hinder the anaerobic digestion process in the ASBR as much as the resulting OLR does. Therefore, we can state that as long as the OLR is within the limits, in our case less than $13.6 \mathrm{~kg} /\left(\mathrm{m}^{3} \cdot\right.$ day $)$, anaerobic digestion can be operated safely using any yeast volume fraction up to $17 \%$ in a single cycle. This confirms that ASBR is more suitable for anaerobic digestion of yeast at higher ratios than $1.1 \%$ (by volume) than the EGSB reactor. 
Table 2. Mass fractions of volatile fatty acids in experiments

\begin{tabular}{|c|c|c|c|c|c|c|c|c|c|}
\hline \multirow{2}{*}{$\begin{array}{l}\text { Experiment/ } \\
\text { cycle }\end{array}$} & \multicolumn{9}{|c|}{$w($ acid $) /(\mathrm{mg} / \mathrm{kg})$} \\
\hline & Acetic & Propionic & Isobutyric & $n$-Butyric & Valeric & $\begin{array}{l}\text { 4-Methyl- } \\
\text { valeric }\end{array}$ & Capronic & Heptanoic & Total \\
\hline $1 / 4$ & b.d.l. & b.d.l. & b.d.l. & b.d.l. & b.d.l. & b.d.l. & b.d.l. & b.d.l. & b.d.l. \\
\hline $2 / 4$ & b.d.l. & b.d.l. & b.d.l. & b.d.l. & b.d.l. & b.d.l. & b.d.l. & b.d.l. & b.d.l. \\
\hline $3 / 4$ & b.d.l. & b.d.l. & b.d.l. & b.d.l. & b.d.l. & b.d.l. & b.d.l. & b.d.l. & b.d.l. \\
\hline $4 / 4$ & $2 \pm 1$ & $1 \pm 1$ & $8 \pm 2$ & $1 \pm 1$ & b.d.l. & b.d.l. & b.d.l. & $11 \pm 5$ & $24 \pm 5$ \\
\hline $5 / 4$ & $4 \pm 1$ & $5 \pm 1$ & $211 \pm 59$ & $320 \pm 93$ & $126 \pm 44$ & $1 \pm 1$ & $18 \pm 6$ & $9 \pm 4$ & $955 \pm 153$ \\
\hline $6 / 4$ & $5 \pm 1$ & $7 \pm 1$ & $303 \pm 106$ & $607 \pm 212$ & $184 \pm 64$ & $4 \pm 1$ & $27 \pm 7$ & $6 \pm 2$ & $1611 \pm 242$ \\
\hline $7 / 5$ & $7 \pm 1$ & $4 \pm 1$ & $345 \pm 121$ & $193 \pm 68$ & $194 \pm 69$ & $276 \pm 97$ & $28 \pm 7$ & $1 \pm 1$ & $1429 \pm 229$ \\
\hline $8 / 5$ & $260 \pm 13$ & $701 \pm 95$ & $341 \pm 120$ & $882 \pm 296$ & $185 \pm 59$ & $397 \pm 115$ & $17 \pm 4$ & $2 \pm 1$ & $3160 \pm 474$ \\
\hline
\end{tabular}

b.d.1.=below detection limit

\section{Additional concerns and impacts}

Although the anaerobic digestion of brewer's yeast has been proven to be feasible, some additional concerns should be addressed. The biomass growth was estimated after experiment 6 and compared to the biomass growth in the EGSB reactor treating brewery wastewater from which the inoculum was collected. The biomass growth was 0.110 and $0.123 \mathrm{~kg}$ of TS per $\mathrm{kg}$ of tCOD, added and degraded, respectively, whereas in the EGSB reactor 0.087 $\mathrm{kg}$ of TS per $\mathrm{kg}$ of tCOD were added (13). This increase can be attributed partially to the higher OLR (the EGSB reactor was operating at an average OLR of $4.0 \mathrm{~kg} /$ $\left(\mathrm{m}^{3} \cdot\right.$ day $\left.)\right)$, but mainly to the accumulation of degraded yeast solids. Although no adverse effects were observed as a consequence of the accumulation of solids, a longer-term study should be performed in order to confirm whether there are any negative effects after longer-term operation. The excess biomass was removed after experiment 6 and there were no negative effects on the process observed in experiment 7 .

The yeast has a $\gamma(\mathrm{TKN})=(12.0 \pm 1.0) \mathrm{g} / \mathrm{L}$, which may cause some problems in terms of ammonia inhibition (22) as well as in any subsequent aerobic treatment, which is a conventional step in brewery wastewater treatment. In our research, we observed maximum mass concentrations of $\mathrm{NH}_{4}-\mathrm{N}$ and TKN of 2250 and $2630 \mathrm{mg} / \mathrm{L}$, respectively, at the maximum ratio of yeast/wastewater mixture of 22 $\%$ (by volume). The mass concentrations of $\mathrm{NH}_{4}-\mathrm{N}$ and TKN were much lower at cycles with lower yeast/wastewater mixture ratio (data shown in Table 1). These concentrations were well below the ammonia inhibition limit, which according to Chen et al. (22) is between 1400 and $4000 \mathrm{mg} / \mathrm{L}$. The ratio of yeast in the yeast/wastewater mixtures of our interest was up to $17 \%$ (by volume); therefore, it does not constitute any concern regarding ammonia inhibition. However, such anaerobic digestion of yeast represents a several-fold increase in the nitrogen load in aerobic treatment, which usually follows such anaerobic digestion. The results of the presented study were extrapolated to the brewery wastewater treatment plant where the substrates were collected, and the nitrogen content in the aerobic treatment stage increased on average by $60 \%$. This is a considerable increase and it should be considered. Analyses of samples of the substrates taken from the full-scale plant operation, anaerobically digesting all the excess brewer's yeast available (14), showed that in the case of local brewery such an increase of nitrogen load was well managed in the aerobic treatment stage with no significant increases in the used resources. Moreover, yeast digested to biogas can offer up to a $50 \%$ increase of natural gas/biogas substitution ratio, which can be increased from $20(8)$ to $30 \%$.

\section{Conclusions}

Employing an anaerobic sequencing batch reactor (ASBR) is an effective way of using brewer's yeast as an energy co-substrate for the biogas production, which can then substitute natural gas used in the breweries. In comparison with digesting the yeast in an expanded granular sludge bed (EGSB) reactor, where maximum allowable volume ratio of yeast/wastewater mixture was $1.1 \%$, much higher volume ratios of yeast/wastewater mixture can be applied in the presented ASBR system. Up to $8 \%$ (by volume) yeast in yeast/wastewater mixture presented no adverse effects in anaerobic digestion. Applying mixtures with volume ratios of 9-12\%, process performance slightly diminished; however, it was still satisfactory. Higher volume ratios of yeast/wastewater mixture require longer than 1-day cycle to be successful. Maximum viable anaerobic digestion process was achieved with yeast/wastewater mixture volume ratio of $17 \%$. This corresponds to organic loading rate (OLR) of $13.6 \mathrm{~kg} /$ $\left(\mathrm{m}^{3} \cdot\right.$ day $)$, where we can conclude that this is the maximum organic load in one cycle under which the anaerobic process of this type can operate safely. Moreover, the anaerobic digestion process is more affected by the OLR than by the yeast ratio in the mixture; therefore, in such operation the main attention should be given to the OLR in the process. The mass concentrations of $\mathrm{NH}_{4}-\mathrm{N}$ and TKN in the influent and effluent do not represent a significant obstacle at achieved OLR. They are below inhibition limit and the increase to aerobic stage can be managed with optimisation of the aerobic process.

By extrapolating the experimental results to the conditions of the local brewery, an increase in biogas production and natural gas substitution of up to $50 \%$ could be achieved. The application of the presented technology 
may offer substantial savings in terms of financial and energy resources in the brewing process.

\section{References}

1. Bocken NMP, Allwood JM. Strategies to reduce the carbon footprint of consumer goods by influencing stakeholders. J Clean Prod. 2012;35:118-29. https://doi.org/10.1016/j.jclepro.2012.05.031

2. McHugh S, O'Reilly C, Mahony T, Colleran E, O'Flaherty V. Anaerobic granular sludge bioreactor technology. Rev Environ Sci Biotechnol. 2003;2:225-45. https://doi.org/10.1023/B:RESB.0000040465.45300.97

3. Connaughton S, Collins G, O'Flaherty V. Psychrophilic and mesophilic anaerobic digestion of brewery effluent: a comparative study. Water Res. 2006;40:2503-10. https://doi.org/10.1016/j.watres.2006.04.044

4. Baloch MI, Akunna JC, Collier PJ. The performance of a phase separated granular bed bioreactor treating brewery wastewater. Bioresour Technol. 2007;98:1849-55. https://doi.org/10.1016/j.biortech.2006.06.014

5. Zoutberg GR, de Been P. The Biobed ${ }^{\circledR}$ EGSB (Expanded Granular Sludge Bed) system covers shortcomings of the upflow anaerobic sludge blanket reactor in the chemical industry. Water Sci Technol. 1997;35:183-7. https://doi.org/10.1016/S0273-1223(97)00268-0

6. Shao X, Peng D, Teng Z, Ju X. Treatment of brewery wastewater using anaerobic sequencing batch reactor (ASBR). Bioresour Technol. 2008;99:3182-6. https://doi.org/10.1016/j.biortech.2007.05.050

7. Mahmoud N, Zeeman G, Gijzen H, Lettinga G. Solids removal in up-flow anaerobic reactors, a review. Bioresour Technol. 2003;90:1-9. https://doi.org/10.1016/S0960-8524(03)00095-6

8. Kormelinck VG. Optimum wastewater treatment at Paulaner Munich. Brauwelt Int. 2003;6:387-90.

9. Agler MT, Aydinkaya Z, Cummings TA, Beers AR, Angenent LT. Anaerobic digestion of brewery primary sludge to enhance bioenergy generation: a comparison between low- and high-rate solids treatment and different temperatures. Bioresour Technol. 2010;101:5842-51. https://doi.org/10.1016/j.biortech.2010.03.023

10. Bocher BT, Agler MT, Garcia ML, Beers AR, Angenent LT. Anaerobic digestion of secondary residuals from an anaerobic bioreactor at a brewery to enhance bioenergy generation. J Ind Microbiol Biotechnol. 2008;35:321-9. https://doi.org/10.1007/s10295-007-0295-4
11. Mussatto SI, Dragone G, Roberto IC. Brewers' spent grain: generation, characteristics and potential applications. J Cereal Sci. 2006;43:1-14. https://doi.org/10.1016/j.jcs.2005.06.001

12. Neira $K$, Jeison D. Anaerobic co-digestion of surplus yeast and wastewater to increase energy recovery in breweries. Water Sci Technol. 2010;61:1129-35. https://doi.org/10.2166/wst.2010.052

13. Zupančič GD, Škrjanec I, Marinšek-Logar R. Anaerobic codigestion of excess brewery yeast in a granular biomass reactor to enhance the production of biomethane. Bioresour Technol. 2012;124:328-37. https://doi.org/10.1016/j.biortech.2012.08.064

14. Zupančič GD, Roš M, Klemenčič M, Oset M, Marinšek-Logar R. Biogas production from brewery yeast in an EGSB reactor. Brauwelt Int. 2016;34:108-13.

15. Standard methods for the examination of water and wastewater, 21st edition. Washington, DC, USA: American Public Health Association (APHA). Denver, CO, USA: American Water Works Association (AWWA). Alexandria, VA, USA: Water Environment Fedration (WEF); 2005.

16. ISO 6060:1989. Water quality - Determination of the chemical oxygen demand. Geneva, Switzerland: International Organization for Standardization (ISO); 1989.

17. Holdeman LV, Cato EP, Moore WEC. Anaerobe laboratory manual. Blacksburg, VA, USA: Virginia Polytechnic Institute; 1977. pp. 1-156.

18. Drolc A, Cotman M, Ros M, Majcen N. Measurement traceability and its role in proficiency testing schemes - a case study for wastewater analysis in Slovenia. Accred Qual Assur. 2006;11:455-61. https://doi.org/10.1007/s00769-006-0112-1

19. Drolc A, Cotman M, Roš M. Uncertainty of chemical oxygen demand determination in wastewater samples. Accred Qual Assur. 2003;8:138-45. https://doi.org/10.1007/s00769-002-0565-9

20. JCGM 100:2008: Evaluation of measurement data - Guide to the expression of uncertainty in measurement. Geneva, Switzerland: International Organization for Standardization (ISO); 2008.

21. Zupančič GD, Stražiščar M, Roš M. Treatment of brewery slurry in thermophilic anaerobic sequencing batch reactor. Bioresour Technol. 2007;98:2714-22. https://doi.org/10.1016/j.biortech.2006.09.044

22. Chen Y, Cheng JJ, Creamer KS. Inhibition of anaerobic digestion process: a review. Bioresour Technol. 2008;99:4044-64. https://doi.org/10.1016/j.biortech.2007.01.057 